\title{
Design Optimization of a Composite Rebar for the Reinforcement of Concrete
}

\author{
Suong V. Hoa and Yu Xin \\ Concordia Center for Composites \\ Department of Mechanical Engineering \\ Concordia University \\ hoasuon@vax2.concordia.ca
}

\begin{abstract}
This paper presents the design optimization for a new composite rod for the reinforcement of concrete. This rod has a wavy shape with lobes that provide positive mechanical interlock with the concrete when the rod is embedded in concrete. ANSYS finite element program is used for the calculation of stresses. One particular set of concrete properties and one particular set of composite properties are used. Lobes of spherical shapes are examined. Rods under uniaxial tension loading are studied. The result gives the optimal ratio between the lobe radius and the rod radius.
\end{abstract}

\section{Introduction}

The most commonly used construction material throughout the world is prestressed and non-prestressed steel reinforced concrete. Generally steel is very durable. However, for structures in highly aggressive environments over long time, the protection surrounding the steel rod may break down and corrosion may take place. This may lead to cracking and spalling of the concrete and the structure will become unserviceable or unsafe [1]. In an effort to provide products that may not have the corrosion problem as steel rods, civil engineers have attempted to use fiberglass reinforced polyester rods in place of the steel rods [2]. These fiberglass reinforced polyester rods are usually made by pultrusion process where fibers impregnated with wet resins are pulled through a heated die. As these materials go through the heated die, they solidify and cure, yielding rods that are strong in the axial direction. Figure 1 shows the picture of a few of these rods. The arrival of these pultruded fiber reinforced plastic (FRP) rods have brought a lot of excitement to the civil engineering community since the early 1990s [3]. They seemed to provide answer to the corrosion of steel rods and promised to provide great savings in terms of down time required for the digging up and painting the steel rods once in a while in the field. They are also light weight ( $20 \%$ of the density of steels). However, as these rods were being experimented and tested, many issues came up. These are summarized as follows:

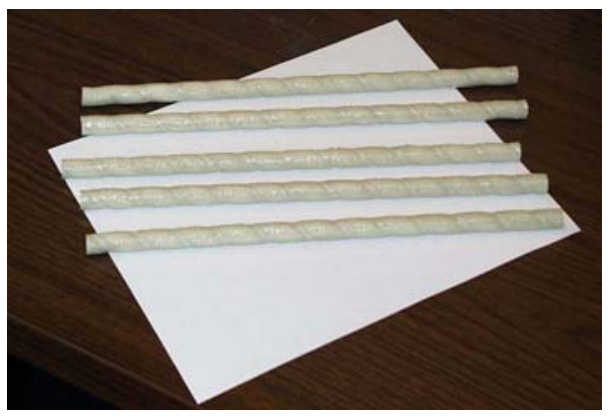

Figure 1. Fiber reinforced plastic (FRP) rebars 
In order to produce rods that are low cost so that the product can be competitive with currently used steel rods, fiberglass and polyester are used. However it was found that fiberglass is attacked by alkali inherently present in the concrete [4]. The degree of attack is increased by the presence of applied stress. The promoters of these rods argue that at low stress levels, the durability of these rods can be a long time. This argument has convinced a few users of the civil infrastructures to try out these rods in some concrete structures. However this concern is always there and in order to allay this problem, a better design is necessary. For rods made of polyester resin, it is very difficult to bend the rod due the fact that thermoset resin (polyester) cannot be deformed by heating. This creates a practical problem for field applications. Even for rods made of glass/polyester, the cost of rods is still high compared to the steel rods.

As a response to these challenges, Hoa [5] has designed a new fiber reinforced plastic rod for the reinforcement of concrete. This new rod has a wavy shape as shown in Figure 2. It has lobes that provide positive mechanical interlock with the concrete. The advantages of this new design as compared to previous designs are presented in an accompanying paper [5]. This rod is manufactured using a different technique from pultrusion. The manufacturing technique for this rod is described in [6].

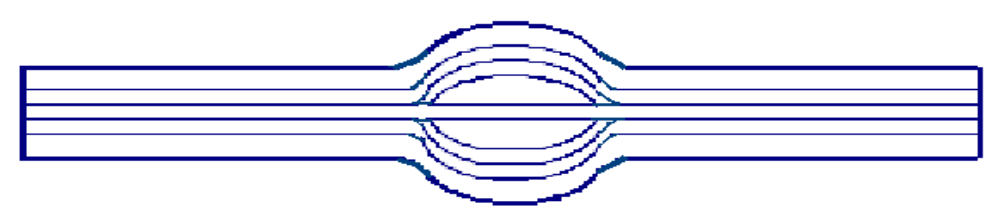

Figure 2. A schematic of the configuration of new design

The works by Hoa $[5,6]$ provide the concepts and test results for the new rod, which show its potential for usage. However, the design of the rod is not optimized. It is desirable to know what are the shape parameters for the rod that can provide high resistance to applied load. This paper presents a portion of work done on the determination of optimal parameters for wavy rods with spherical shaped lobes. [7].

\section{Material Properties}

The materials for the reinforcing system consists of the composite and the concrete.

\section{Concrete Properties}

Concrete properties are shown in Table 1.

Table 1. Properties of concrete $\mathbf{C 6 0}$ [8]

\begin{tabular}{|c|c|c|c|c|c|}
\hline $\begin{array}{c}\text { Young's } \\
\text { Modulus } \\
\text { (GPa) }\end{array}$ & $\begin{array}{c}\text { Poisson's } \\
\text { ratio }\end{array}$ & $\begin{array}{c}\text { Compressive } \\
\text { strength } \\
\text { (MPa) }\end{array}$ & $\begin{array}{c}\text { Tensile } \\
\text { strength } \\
\text { (MPa) }\end{array}$ & $\begin{array}{c}\text { Shear } \\
\text { strength } \\
\text { (MPa) }\end{array}$ & $\begin{array}{c}\text { Expansion } \\
\text { coefficient } \\
\left(/ /{ }^{\circ} \mathbf{C}\right)\end{array}$ \\
\hline 36 & 0.17 & 27.5 & 3.15 & 3.10 & $12.0 \times 10^{-6}$ \\
\hline
\end{tabular}


In addition, it is also important to consider the shrinkage of concrete. This is because the interaction between the rod and concrete comes mainly due to the compression force between the rod and concrete. This compression pressure comes from the shrinkage of concrete upon curing.

\section{Shrinkage of concrete}

When cement reacts with water part of the water is chemically combined, but the remainder dries out, causing the set cement to shrink. It is termed drying shrinkage [9]. When rebars are embedded in concrete during manufacturing, the shrinkage of concrete produces compressive stresses on the rebar. For the simulation of the interaction between rebar and concrete, this shrinkage needs to be incorporated into the model. The chemical shrinkage of concrete can be simulated as shrinkage due to decrease in temperature. According to Carreira et al. [9], the equivalence between chemical shrinkage and shrinkage due to temperature drop $\Delta \mathrm{T}$ is related by the following equations (1) and (2) (based on equality of strains):

$\varepsilon_{\text {shu }}=1.2 \varepsilon_{\text {sh } 6}\left(1-\mathrm{H}^{3}\right) \mathrm{e}^{(-0.12 \mathrm{Ac} / \mathrm{Pc})}$

$\Delta \mathrm{T}=\varepsilon_{\text {shu }} / \mathrm{e}_{\mathrm{th}}$

where:

$\varepsilon_{\text {shu } \quad \text { Shrinkage strain }}$
$\varepsilon \operatorname{sh} 6$
Shrinkage strain from standard 6 inches $(150 \mathrm{~mm})$ cylinder shape test specimens, in micro-strains.
$\mathrm{Ac} / \mathrm{Pc} \quad$ Cross sectional area-to-perimeter ratio of specimen, in inches.
$\mathrm{H}$
Ambient average relative humidity as a decimal.
$\mathrm{e}_{\text {th }}$
Coefficient of thermal expansion for the concrete
$\Delta \mathrm{T} \quad$ Temperature drop

For a specimen with square cross section with side $a$, the ratio $\mathrm{Ac} / \mathrm{Pc}$ is $a / 4$. Different types of concrete with different conditions give different results. Carreira et al [9] recommended that the equivalent temperature drop for ambient relative humidity for different concretes lies within the range of $27^{\circ} \mathrm{C}$ to $49^{\circ} \mathrm{C}$.

\section{Properties of composite materials}

The material used for the manufacture of the modified rebar is made of carbon/nylon, a thermoplastic composite. Due to the lack of characterization data for this material, for simulation purpose, the properties of NCT 301 carbon/epoxy is used. The change in the matrix material for the composite has more influence on the ductility and environmental performance of the material rather than the elastic properties used here. The results will therefore be valid for other matrix materials. It is assumed that all fibers in the rod are uniaxial along the length of the rod. Properties of the composites are shown in Table 2.

Table 2. Properties of FRP rod (Made by NCT 301) [10]

\begin{tabular}{|c|c|}
\hline Young's Modulus E E $_{1}(\mathrm{GPa})$ & 113.9 \\
\hline Young's Modulus $E_{2}(G P a)$ & 7.985 \\
\hline Young's Modulus $E_{3}(G P a)$ & 7.985 \\
\hline Poisson's ratio $v_{12}$ & 0.29 \\
\hline Poisson's ratio $v_{32}$ & 0.4 \\
\hline Shear modulus $\mathrm{G}_{12}(\mathrm{MPa})$ & 3137 \\
\hline Shear modulus $\mathrm{G}_{23}(\mathrm{MPa})$ & 2852 \\
\hline Tensile strength (MPa) & 9000 \\
\hline Expansion coefficient $\alpha\left(/{ }^{\circ} \mathrm{C}\right)$ & $24.3 \times 10^{-6}$ \\
\hline
\end{tabular}




\section{Numerical Method and Model}

ANSYS $^{\circledR}$ program was used for the geometry modeling and the calculation of stresses. For both the concrete and FRP rebar, the elements used are SOLID92 3-D 10-Node Tetrahedral Structural Solid. This is a pyramidal element. The reason why this element was selected (rather than the regular hexahedral element) is due to the presence of the lobe which irregularizes the geometrical mesh.

\section{Contact elements}

Microscopic observation of the interface between the composite rod and concrete shows that the interaction between concrete and composite is mainly due to friction and there is no chemical interaction. The interaction between the composite rod and concrete is mainly a contact problem. As such, the connection between the composite rod and the concrete can not be accurately modeled by rigid nodes. Contact elements need to be used. The numerical modeling of contact surfaces can be done by either the Lagrange multiplier method or the Penalty method [11]. ANSYS software uses the Augmented Lagrange multiplier method for modeling the contact situation. Figure 3 shows the finite element mesh.

Solid 92 3-D 10-Node element

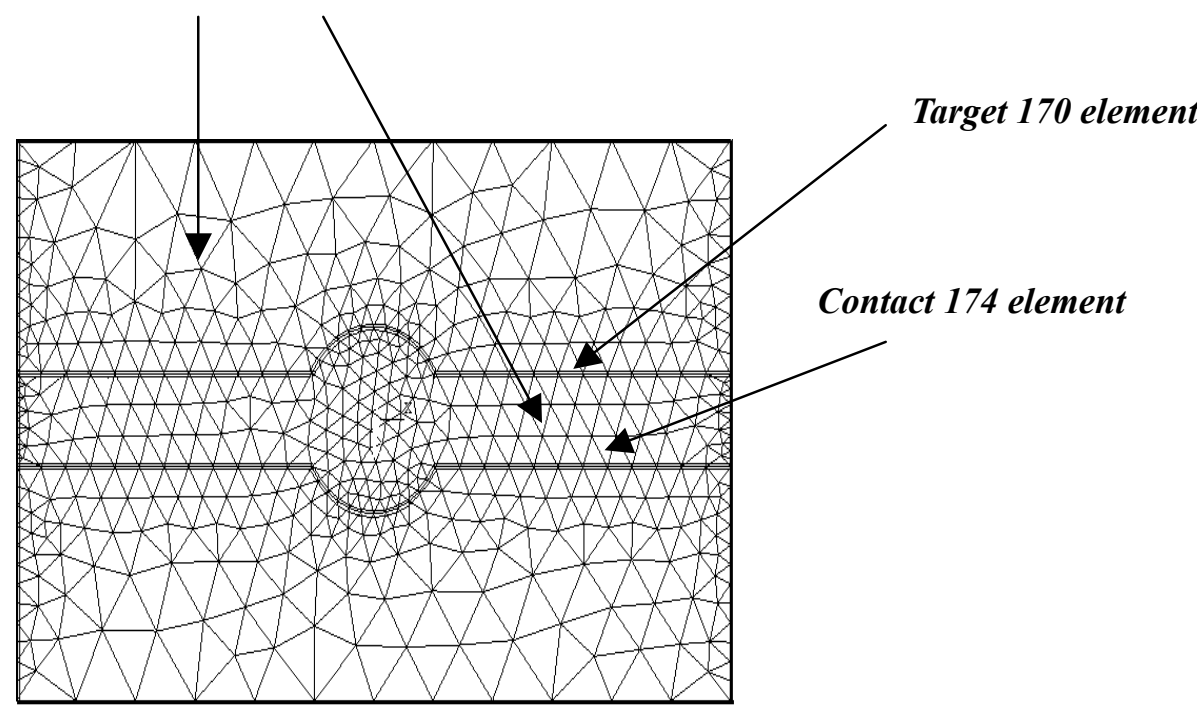

Figure 3. Finite element mesh for the material system

\section{Model Dimensions}

The dimensions of the model are based on samples already made for experimentation. A concrete cylinder of $33 \mathrm{~mm}$ radius and $110 \mathrm{~mm}$ in length was considered. Dimensions are: Rod radius $r=5.5 \mathrm{~mm}$, Lobe radius $R_{\mathrm{c}}=33 \mathrm{~mm}, \quad$ Length of $\operatorname{rod} L_{\mathrm{b}} \quad=$ Length of concrete
$L_{\mathrm{c}}=110 \mathrm{~mm}$.

\section{Loading and Boundary conditions}

Due to symmetric configuration of the system, one quarter of the system may be considered. Figure 4 shows the configuration of the model and boundary conditions. 


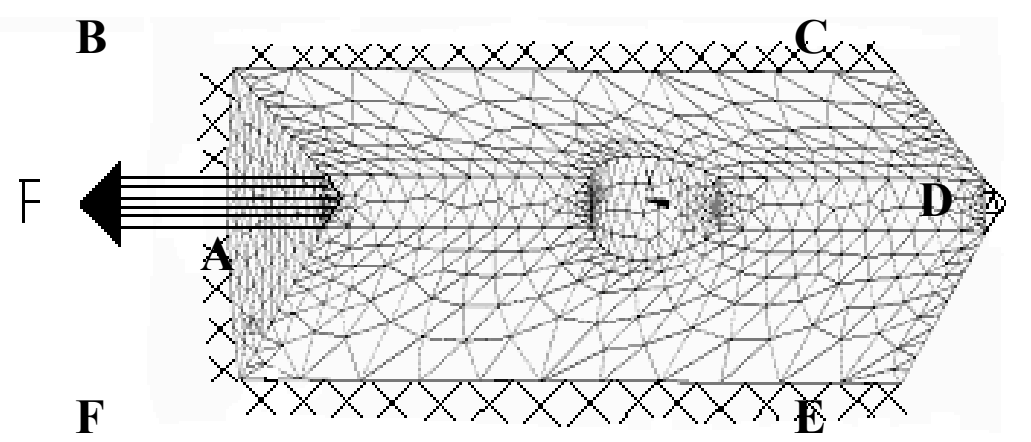

Figure 4. Loading and Boundary conditions of the model

Loading and boundary conditions are similar to testing conditions. Concrete is constrained on face $\mathrm{ABF}$ as axial load $F$ is applied. Assuming that the concrete is constrained on its surface BCEF due to the surrounding, nodes on this surface are fixed. Also, symmetric displacement are applied on both surfaces $\mathrm{ABCD}$ and ADEF. Force $F$ was given a value of $600 \mathrm{~N}$.

\section{Shrinkage simulation}

It was mentioned above that chemical shrinkage of concrete may be replaced with temperature drop for the purpose of numerical modeling. It was also mentioned that the temperature drop may be within the range of 27 ${ }^{\circ} \mathrm{C}$ to $49{ }^{\circ} \mathrm{C}$ for different types of concrete. This temperature drop range is for pure material consideration. When thick geometry is taken into consideration, other parameters enter into the picture. For a block of concrete, shrinkage occurs more rapidly at the surface than at the center of the specimen. The shrinkage of a block of concrete therefore depends on the geometry of the specimen. Different temperature drops were tried out. It was found that if a temperature drop within the above range is used, cracking in the concrete occurs. In order to obtain a working temperature drop, a smaller value needs to be used. It was found from the calculated results that when the temperature drop is greater than $7{ }^{\circ} \mathrm{C}$, models with different lobe radii fail due to concrete crack (Tensile or shear stresses exceed the strengths). Consequently, $7{ }^{\circ} \mathrm{C}$ drop was used to simulate the shrinkage in this study.

\section{Modification of model to accommodate both shrinkage and mechanical loading}

In the above discussion, cooling down the concrete may simulate the effect of drying shrinkage. However, during this cooling, points on the surface $\mathrm{ABF}$ shown in Figure 5 will change their positions. At the same time for mechanical loading, it is necessary to constrain all points on surface ABF. Also, during cooling the outer surface of the concrete will move in. This contradicts with the assumption that the outer surface of the concrete specimen is fixed due to its surrounding. This contradiction in the boundary conditions requires modification of the model. Rather than cooling the concrete, the rod was heated up. The radial compressive stresses between the concrete and the composite rebars are calculated for both cases. If the radial compressive stresses at the interface between the rebar and concrete are the same in both cases (Cooling down the concrete or heating up the rebar) then it is assumed that the interaction effect is the same. Figure 5 illustrates the configuration for both cases. 
Model A.

Cooling concrete

only $\left(7^{\circ} \mathrm{C}\right)$
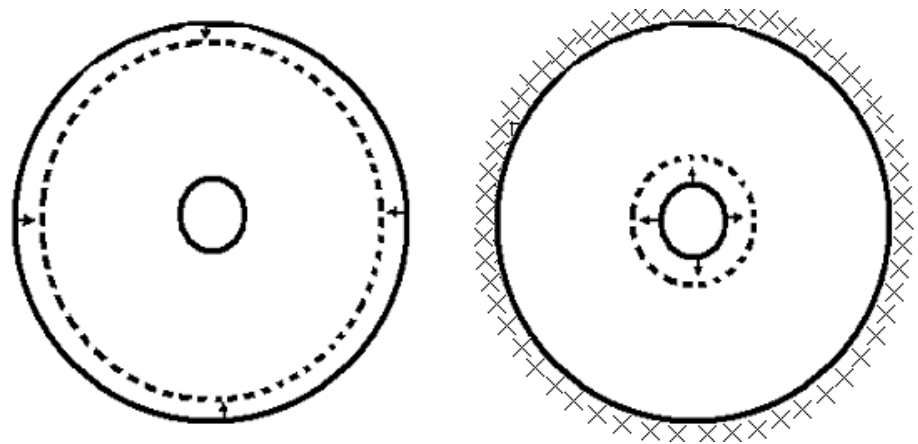

Model B.

Heating rebar only

$\left(5^{\circ} \mathrm{C}\right)$

Figure 5: Drying shrinkage in simulation

The center line of the FRP rebar was constrained from any radial motion. Cooling concrete only $\left(7{ }^{\circ} \mathrm{C}\right)$ is illustrated in Figure 5 model A. Constraining the outside surface of concrete and heating rebar only $\left(5{ }^{\circ} \mathrm{C}\right)$ is illustrated in Figure 5 model B. Figure 6 shows the radial compressive stress obtained from both cases. It can be seen that cooling concrete only $\left(7^{\circ} \mathrm{C}\right)$ gives the same interface compression stresses as the case of constraining the surface of concrete then heating rebar only $\left(5{ }^{\circ} \mathrm{C}\right)$. The results are comparable within $6 \%$, which is acceptable in this work. Model B was used in this work.

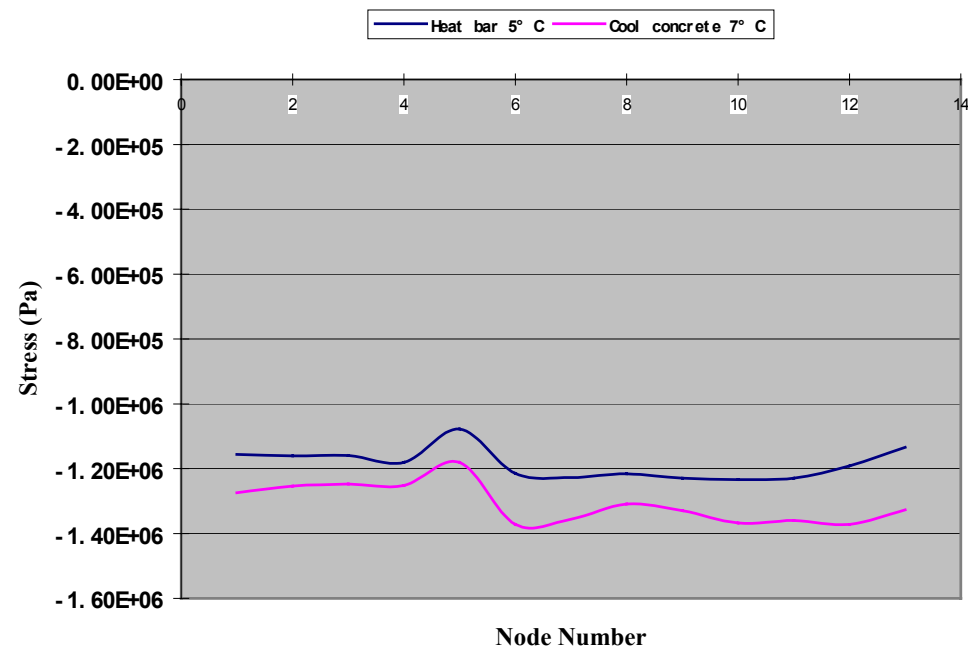

Figure 6. Radial compression stress between the concrete and FRP rebar for the two models

\section{Optimization Parameter}

The main objective in introducing the lobe in the rebar is to enhance the mechanical interlock between the rebar and the concrete. Without the lobe, the main force holding the rebar in the concrete is the friction between the two components. If the shear stress at the interface between the rebar and the concrete exceeds the interfacial shear strength, slipping occurs and the effectiveness of the rebar as a reinforcement is diminished if not eliminated. The mechanical interlock between the wavy rebar and the concrete depends on the difference between the size of the lobe and the radius of the rebar. The larger is the difference between the size of the lobe and the radius of the rebar, the large is the mechanical interlock. On the other hand, as this difference increases, the compressive stresses (on the forward side of the lobe) and tensile stresses (on the rearward side of the lobe) in the concrete will increase. Too large of a difference between the size of the lobe and the radius of the concrete will make the concrete fail earlier. The strength of the whole system of 
rebar/concrete will be lower and this defeats the purpose of the reinforcement. It is therefore important to optimize the shape of the lobe such that the largest strength of the system can be obtained. The parameters for the optimization would be the ratios between the stresses/strengths for shear at the interface and the tensile/compressive failure of concrete. An optimal design is one that provides the maximum degree of mechanical interlock without early concrete failure. The objective is to change the lobe shape parameters to obtain maximum pull-out force without tensile failure in the concrete nor slipping at interface. The optimization will be to determine the best ratio between the radii of FRP rebar and lobe $(R / r)$.

Maximum strength criteria will be used to determine failure. The stresses for each failure mode will be compared against the strengths for that mode.

\section{Optimal Parameters for Spherical-shape -lobed Rebars}

Solid rod. Ratio $R / r$ :Value of $r$ is kept constant at 5.5 $\mathrm{mm}$. Five values of $R$ are considered. These are $9 \mathrm{~mm}$, $10 \mathrm{~mm}, 11 \mathrm{~mm}, 12 \mathrm{~mm}$, and $13 \mathrm{~mm}$ respectively. From the results it was found that the ratio of stress/strength in the concrete is always higher than the similar ratio of stress/strength in the FRP rebar. For example, for the case where $R=11 \mathrm{~mm}$, Tables 3 and 4 show the results for the stresses and stress/strength ratios in both the concrete and in the rebar. The tensile stress ratio in the concrete is $45 \%$ as compared to the similar ration in FRP of $1.1 \%$. The compressive stress ratio in concrete is $25 \%$ as compared to a similar ration in FRP of 5.5\%. Also the ratio for shear stress in concrete is $70 \%$ as compared to a similar ration in FRP of $4.3 \%$. As such, to reduce the number of presented results, only the results for concrete will be shown in subsequent sections.

Table 3. Stress/strength ratio for concrete for lobe radius $=11 \mathrm{~mm}$

\begin{tabular}{|c|c|c|c|c|c|}
\hline $\begin{array}{c}\text { Tensile } \\
\text { strength } \\
\text { (MPa) }\end{array}$ & 3.15 & $\begin{array}{c}\text { Maximum } \\
\text { Tensile stress }\end{array}$ & 1.42 (Node 4182) & $\begin{array}{c}\text { Stress / } \\
\text { strength }\end{array}$ & $45 \%$ \\
\hline $\begin{array}{l}\text { Compressive } \\
\text { strength } \\
\text { (MPa) }\end{array}$ & 27.50 & $\begin{array}{c}\text { Maximum } \\
\text { Compressive } \\
\text { stress }\end{array}$ & 6.77 (Node 3863) & $\begin{array}{c}\text { Stress / } \\
\text { strength }\end{array}$ & $25 \%$ \\
\hline $\begin{array}{c}\text { Shear } \\
\text { strength } \\
\text { (MPa) }\end{array}$ & 3.10 & $\begin{array}{l}\text { Maximum } \\
\text { Shear stress }\end{array}$ & 2.17 (Node 4177) & $\begin{array}{c}\text { Stress / } \\
\text { strength }\end{array}$ & $70 \%$ \\
\hline
\end{tabular}

Table 4. Stress/strength ratio of FRP rebar when lobe radius is $11 \mathrm{~mm}$

\begin{tabular}{|c|c|c|c|c|c|c|c|c|}
\hline \multirow{3}{*}{$\begin{array}{c}\text { Tensile } \\
\text { strength } \\
\text { (MPa) }\end{array}$} & SX & 972.6 & \multirow{3}{*}{$\begin{array}{c}\text { Maximum } \\
\text { Tensile stress } \\
\text { (MPa) }\end{array}$} & SX & 10.56 & \multirow{3}{*}{$\begin{array}{c}\text { Stress / } \\
\text { strength }\end{array}$} & SX & $1.1 \%$ \\
\hline & SY & 28.98 & & SY & 1.60 & & SY & $5.5 \%$ \\
\hline & SZ & 28.98 & & SZ & 1.36 & & SZ & $4.7 \%$ \\
\hline \multirow{3}{*}{$\begin{array}{l}\text { Shear } \\
\text { strength } \\
\text { (MPa) }\end{array}$} & SXY & 19.98 & \multirow{3}{*}{$\begin{array}{c}\text { Maximum } \\
\text { Tensile stress } \\
\text { (MPa) }\end{array}$} & SXY & 0.34 & \multirow{3}{*}{$\begin{array}{c}\text { Stress / } \\
\text { strength }\end{array}$} & SXY & $1.7 \%$ \\
\hline & SYZ & 12.3 & & SYZ & 0.53 & & SYZ & $4.3 \%$ \\
\hline & SXZ & 12.3 & & SXZ & 0.86 & & SXZ & $7.0 \%$ \\
\hline
\end{tabular}


Table 5. Stress/strength ratios in concrete for 5 models of FRP rebar with spherical-shaped lobe

\begin{tabular}{|c|c|c|c|}
\hline & Tensile strength (MPa) & $\begin{array}{c}\text { Compressive strength } \\
\text { (MPa) }\end{array}$ & Shear strength (MPa) \\
\hline Strength & 3.15 & 27.50 & 3.10 \\
\hline Lobe radius $R$ & $\begin{array}{c}\text { Maximum Tensile stress } \\
\text { / Tensile strength }\end{array}$ & $\begin{array}{c}\text { Maximum Compressive } \\
\text { stress / Compressive } \\
\text { strength }\end{array}$ & $\begin{array}{c}\text { Maximum Shear stress / } \\
\text { Shear strength }\end{array}$ \\
\hline $9 \mathrm{~mm}$ & $46.3 \%$ & $\mathbf{2 8 . 9 \%}$ & $\mathbf{1 1 7 . 7 \%}$ \\
\hline $10 \mathrm{~mm}$ & $45.4 \%$ & $\mathbf{2 9 . 4 \%}$ & $\mathbf{7 1 . 2 \%}$ \\
\hline $11 \mathrm{~mm}$ & $45.0 \%$ & $\mathbf{2 4 . 6 \%}$ & $\mathbf{7 2 . 5 \%}$ \\
\hline $12 \mathrm{~mm}$ & $45.7 \%$ & $\mathbf{2 6 . 0} \%$ & $\mathbf{7 0 . 6 \%}$ \\
\hline
\end{tabular}

Table 5 shows the stress/strength ratios in concrete for the five models. Figure 7 shows the comparison chart. It can also be seen from Table 5 that the ratio between maximum stress/tensile strength does not vary much as the radius $R$ is changed. The same thing can be said for the ratio between maximum compressive stress/compressive strength. This implies that for $R$ larger than $9 \mathrm{~mm}$, the effect of the lobe on the maximum compressive and tensile stresses in the concrete is the same. On the other hand, the maximum shear stress/shear strength ratio drops from $117.7 \%$ when $R=$ $9 \mathrm{~mm}$ to $71.2 \%$ when $R=10 \mathrm{~mm}$ and stays at roughly this value for larger values of $R$. This implies that at smaller lobe radius ( $9 \mathrm{~mm}$ or smaller), the lobe is not large enough to reduce the slipping between the rod and concrete. At lobe radius larger than $9 \mathrm{~mm}$, the size of the lobe is large enough to create mechanical interlock so as to reduce the shear force at the interface to prevent slipping.

\section{Radius of bar is $5.5 \mathrm{~mm}$}

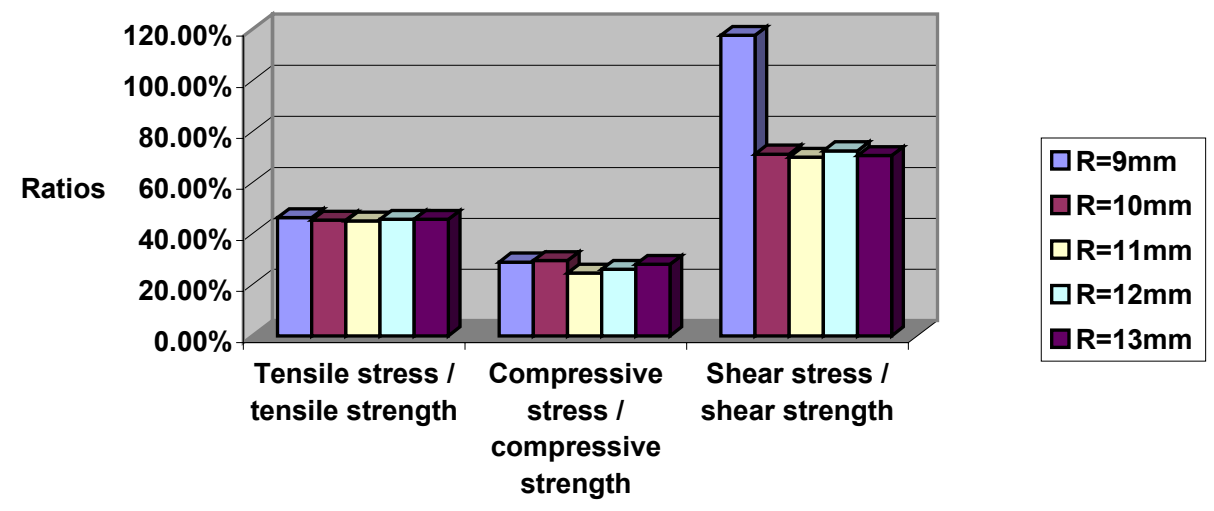

Figure 7. Chart of stress/strength ratios comparison in concrete of 5 models for FRP rebar with spherical-shaped lobe 
It can be seen from figure 7 that the model with $R=$ $11 \mathrm{~mm}$ always has smaller ratios than models with the other four $R$ values. This means that when radius of FRP rebar is $5.5 \mathrm{~mm}$, and spherical-shaped lobe radius is $11 \mathrm{~mm}$, a better condition is obtained. This result can be summarized below as:

For optimal condition: $\mathrm{R} / \mathrm{r}=11 / 5.5=2$

\section{Verification of the optimal ratio for other dimensions of sample}

The above ratio was obtained for the case where $r=5.5$ $\mathrm{mm}$. It is of interest to see if the same ratio applies to the case of other values of $r$. For this purpose, two other values of $r$ are investigated. These are $6 \mathrm{~mm}$ and $6.5 \mathrm{~mm}$. For these cases, the FRP rebar length, concrete length and concrete diameter were also changed proportionately. Values for $R$ are also proportionally changed. For example, for the case where $r=6 \mathrm{~mm}$, values of $R$ are $9.8 \mathrm{~mm}, 10.9 \mathrm{~mm}, 12 \mathrm{~mm}, 13.1 \mathrm{~mm}$ and $14 \mathrm{~mm}$ respectively.

The ratios between the stress/strength for the case where $r=6 \mathrm{~mm}$ is also 2 . This result shows that when radius of the lobe on FRP rebar is $12 \mathrm{~mm}$ the ratio is lowest. One obtains again the optimal ratio: $\mathrm{R} / \mathrm{r}=12 / 6=2$. Similar results are also obtained for the case when $r=$ $6.5 \mathrm{~mm}$.

\section{Conclusion}

1. For spherical-shaped lobes, and for lobe radius more than $9 \mathrm{~mm}$ (for rod radius of $5.5 \mathrm{~mm}$ ), the lobe radius has little influence on the tensile stresses and compressive stresses in the concrete.

2. For spherical-shaped lobes, and for lobe radius more than $10 \mathrm{~mm}$ (for rod radius of $5.5 \mathrm{~mm}$ ), the lobe radius has little influence on the shear stresses at the interface between rod and concrete.

3. For spherical shaped lobes, the optimal ratio is $\mathrm{R} / \mathrm{r}=2$.

\section{Acknowledgement}

The financial support from ISIS CANADA (Federal Network of Centers of Excellence on Intelligent Sensing for Innovative Structures) is appreciated.

\section{References}

[1] Muhammad A., "Bond Behavior of Fiber Reinforced Plastic (FRP) Reinforcement with concrete", Ph.D Thesis. The Pennsylvania State University, 1995, pp .1-5.

[2] Benmokrane B., and R. Masmoudi, "FRP C-Bar as Reinforcing Rod for Concrete Structures", Advanced Composite Materials in Bridges and Structures, $2^{\text {nd }}$ International conference, The Canadian Society for Civil Engineering, 1996.

[3] ISIS CANADA, "Reinforcing Concrete Structures with Fibre reinforced Polymers", Design Manual. ISIS Canada Corporation, 2001, pp. 4-1.

[4] Utumoto T., "Durability of FRP as Reinforcement for Concrete Structures", Proc. Advanced Composite Materials in Bridges and Structures Conference, ed. J. Humar and A. Razaqpur, Ottawa, 2001.

[5] Hoa S.V., "Non metallic Reinforcement Member for Reinforcement of a Structure and Process of its Manufacture", International patent number WO 03/001005 A1, 2003.

[6] Hoa S.V., "A New Composite Rod for the Reinforcement of Concrete", submitted, Journal of Composites in Construction, 2003.

[7] Yu Xin, "Design and Optimization of a Composite Rebar for the Reinforcement of Concrete, " Master of Applied Science thesis, Concordia University, 2003.

[8] Akroyd T.N.W., Concrete Properties and Manufacture, Pergamon Press, 1962.

[9] Carreira D.J., M. Daye and L.R. Greening, "Simplified Method to Account for Effects of Creep and Shrinkage in Structural Analysis", Creep and Shrinkage-structural Design Effects, Greyden Press, 2000, pp. 163-164.

[10] Lab test result at Concordia Center for Composites.

[11] Wriggers P., Computational Contact Mechanics, John Wiley \& Sons, 2002. 